2018-07-01

\title{
Climate forcing of regionally-coherent extreme storm impact and recovery on embayed beaches
}

\section{Burvingt, Olivier}

http://hdl.handle.net/10026.1/11476

\author{
10.1016/j.margeo.2018.04.004 \\ Marine Geology \\ Elsevier BV
}

All content in PEARL is protected by copyright law. Author manuscripts are made available in accordance with publisher policies. Please cite only the published version using the details provided on the item record or document. In the absence of an open licence (e.g. Creative Commons), permissions for further reuse of content should be sought from the publisher or author. 
5 Olivier Burvingt, Gerd Masselink, Tim Scott, Mark Davidson and Paul

6 Russell.

\section{Abstract}

8 The effective management of sedimentary coastlines demands a

9 good understanding of the seasonal and inter-annual cycles in beach volumes, as well as the potential impact of extreme events. This paper uses a 10-year time series (2007-2017) of supra- and intertidal beach volume from exposed and cross-shore transport-dominated sites to examine the extent to which beach behaviour is coherent over a relatively large region (100-km stretch of coast) and predictably coupled to incident wave forcing. Over the study period, 10 beaches, exposed to similar wave/tide conditions, but having different sediment characteristics, beach lengths and degrees of embaymentisation, showed coherent and synchronous variations in sediment volumes, albeit at different magnitudes. The sequence of extreme storms of the $2013 / 14$ winter, which represents the most erosive event over at least a decade along most of the Atlantic coast of Europe, is included in the data set, and three years after this winter, 
beach recovery is still on-going for some of the 10 beaches. Poststorm beach recovery was shown to be mainly controlled by poststorm winter wave conditions, while summer conditions consistently contributed to modest beach recovery. Skilful hindcasts of regional changes in beach volume were obtained using an equilibrium-type shoreline model (ShoreFor; Davidson et al., 2013), demonstrating that beach changes are coherently linked to changes in the offshore wave climate and are sensitive to the antecedent conditions. The ShoreFor model can successfully be applied to exposed coastal areas dominated by cross-shore sediment transport, and can also be used as a relatively simple and regional tool for the future management of beaches where coherence in coastal response is observed. Furthermore, a good correlation was found between the beach volume changes and the new climate index WEPA (West Europe Pressure Anomaly; Castelle et al., 2017b), which offers new perspectives for the role and the use of climatic variations proxies to forecast coastline evolution.

\section{Introduction}

Multi-annual and decadal time-series of shoreline and/or beach volume change are becoming increasingly available from around the world (Pye and Blott, 2008; Senechal et al., 2009; Corbella and Stretch,

44 2012; Barnard et al., 2015; Masselink et al., 2016; Scott et al., 2016;

45 Turner et al., 2016; Castelle et al., 2017a; Phillips et al., 2017). In regions with a seasonal wave climate, these time-series generally show regularly alternating periods of beach erosion and accretion in 
response to annual variations in incident wave height and period (Wright et al., 1984; Dubois, 1988; Komar, 1999; Ruggiero et al., 2005). More commonly, however, the temporal coastal behaviour is less regular and governed by processes operating across multiple time scales. Although long-term (100+ years) beach evolution is mainly affected by variations in sea level and sediment supply (Zhang et al., 2002), beach and shoreline behaviour at short- (hours/months) to medium- (months/years) timescales are more impacted by storm events (Ruggiero et al., 2005; Pye and Blott, 2016; Coco et al., 2014; Castelle et al., 2015; Masselink et al., 2015; Scott et al., 2016; Barnard et al., 2017; Harley et al., 2017). Storminess in the North Atlantic, which is characterized by considerable inter-annual and inter-decadal variability was previously shown to be strongly linked to the North Atlantic Oscillation (NAO, Bromirski and Cayan, 2015). However, the NAO index was not correlated to the $2013 / 14$ winter, when a series of extreme storms $\left(H_{s}>5.2 \mathrm{~m}\right)$ in the North Atlantic provided the most energetic winter waves since at least 1948 (Masselink et al., 2016). On the other hand, the West Europe Pressure Anomaly (WEPA), recently proposed by Castelle et al. (2017b), was strongly linked to the $2013 / 14$ winter and therefore serves as a useful proxy for winter wave conditions in this study.

Many beaches along the southwest of England were highly affected by the $2013 / 14$ sequence of storms and the morphological impact has been well documented (Masselink et al., 2015; Scott et al., 2016). Using pre- and post-storm airborne LiDAR datasets over that winter, Burvingt et al. (2017) demonstrated the existence of coherent storm 
response at beaches showing similar exposure to storm waves. This coherent storm response was characterized by medium to large alongshore uniform sediment losses. Short et al. (2014) also showed that synchronous oscillation and rotation were observed over six years at three beaches with the same orientation and length, and exposed to a similar deep water wave climate and tidal regime. This 'regionally representative' behaviour in response to varying and/or changing wave and other climatic forcing, could guide the extent and scope of the ongoing beach monitoring effort required (Bracs et al., 2016). In this paper, a 10-year dataset of RTK-GPS topographic surveys collected at a regional scale from 10 beaches with similar morphodynamic characteristics (Scott et al., 2011), orientation and wave/tide exposure, but contrasting geomorphological boundaries, will be analysed and discussed. This dataset thus gives an opportunity to address the hypothesis of coherent beach behaviour at a regional scale within a context of extreme storms.

Extreme storms, and the recovery period following these events, are of particular relevance in urbanized coastal areas, since beaches naturally act as a coastal buffer (Stive et al., 2002). Beach recovery processes occur over a wide range of timescales: days (Poate et al., 2015); months (Birkemeier, 1979; Wang et al., 2006; Splinter et al., 2011; Yu et al., 2013; Senechal et al., 2015; Phillips et al., 2017); years (Ruggiero et al., 2005; Choowong et al., 2009; Corbella and Stretch, 2012; Suanez et al., 2012; Castelle et al., 2017a); decades (McLean and Shen, 2006; Thom and Hall, 1991; Houser et al., 2015); or may never fully recover if longshore transport dominated the beach 
response with permanent sediment losses. Although beach recovery

101 is often associated with small wave conditions (Komar, 1999;

102 Ruggiero et al., 2005; Bramato et al., 2012; Roberts et al., 2013),

103 relatively energetic waves can be essential for mobilisation/recovery

104 of deep offshore storm bar deposits (Scott et al., 2016). Beach

105 morpho-dynamics, including surf zone, beach and foredune

106 interactions, also control beach recovery. Studies showed the

107 importance of the relationship between the beach and the

108 intertidal/subtidal bar (Houser et al., 2015; Scott et al., 2016; Brooks

109 et al., 2017; Phillips et al., 2017; Ge et al., 2017) and/or subaerial dune

110 systems (Suanez et al., 2012; Houser et al., 2015) in beach recovery.

111 The 10 study sites in this paper were surveyed over 10 years including

112 a period of three years following an extremely energetic winter

113 season, and represent a valuable resource for a better understanding

114 of recovery processes at a regional scale.

115 Predicting coastline response to storms and longer-term seasonal to

116 inter-annual variability in regional wave climate is an ongoing

117 challenge for coastal zone managers, scientists and engineers. A

118 relatively simple equilibrium shoreline model, ShoreFor, was shown

119 to provide skilful hindcasts of coastal change on coastlines dominated

120 by cross-shore sediment transport (Davidson and Turner, 2009;

121 Davidson et al., 2010; Splinter et al., 2014). This model primarily

122 encapsulates beach behaviour forced by wave-driven cross-shore

123 sediment transport, including antecedent hydro-/morphodynamic

124 conditions. Based on these skills, the ShoreFor model is one of the

125 best tools to provide a better understanding and interpretation of 
beach behaviour time series along the exposed and cross-shore dominated 10 beaches presented here.

128 The aim of this paper is to study, over a 10-year period, the regional 129 behaviour of 10 beaches in a context of extreme storms. The first 130 objective is to investigate the hypothesis of multi-annual and regionally coherent beach behaviour at beaches exposed to similar wave forcing. The second objective is to contextualize beach response and volume change to a sequence of extreme storms within a 10-year time frame, and to explore the key factors that controlled beach recovery during the 3 years following these extreme storms. The third objective is to use an equilibrium model to provide a better understanding and interpretation of the link between beach behaviour and wave forcing. The fourth objective is to study the link between North Atlantic climate variability and beach volume change

140 using a climate index controlling winter wave activity along the

141 Atlantic coast of Europe.

\section{Study area, datasets and methodology}

\subsection{Study area}

144 The 10 study sites, located along the north coast of southwest

145 England (Fig. 1), are all high-energy macrotidal sandy beaches that are

146 exposed to swells and wind-waves from the North Atlantic. The wave

147 climate is seasonal with larger waves (mean $H_{s}=2.2 \mathrm{~m}$, mean $T_{p}=11$

$148 \mathrm{~s}$ ) in winter from October to March, and smaller waves (mean $H_{s}=1.4$ m, mean $T_{p}=9 \mathrm{~s}$ ) in summer from April to September (Fig. 1, Table 3 
and 4). The largest waves are generated by extra-tropical storms originating in the mid-latitude westerly wind belt (Lozano et al., 2004), although, occasionally, the coast is also affected by the remnants of tropical cyclones. On average, 17 storm events (peak $H_{s}>4 \mathrm{~m}$ ) and 5 severe storm events (peak $H_{s}>6 \mathrm{~m}$ ) occur annually (Scott, 2009). The extra-tropical storminess is strongly linked to the North Atlantic Oscillation (NAO; Bromirski and Cayan, 2015) and the West Europe Pressure Anomaly (WEPA; Castelle et al., 2017b), which are both characterized by considerable inter-annual and inter-decadal variability (Table 3 and 4).

A diverse set of beach systems is represented by the 10 study sites

(Fig. 2 and Table 1) with the median size of the beach sediment ranging from 0.25 to $0.61 \mathrm{~mm}$. Several beaches are backed by dune systems that vary in size and height (Widemouth \#1, Constantine \#2, Porthcothan \#3, Gwithian \#9 and Sennen \#10) and front high cliffs (Trenance \#4 and Watergate \#5). Relatively large rocky platforms can be found at Widemouth \#1, Constantine \#2 and Fistral \#7 beaches (Fig. 2). All beaches in the data set are constrained by rocky headlands (Fig. 2) and can either be considered as very embayed (Porthcothan \#3 and Porth \#6), semi-embayed (Constantine \#3, Trenance \#4, Fistral \#7 and Porthtowan \#8) or relatively open (Widemouth \#1, Watergate \#5, Gwithian \#9 and Sennen \#10). A beach being considered here as very embayed (relatively open) is when its cross-shore length, from the backshore to mean low water spring level, is more (less) than twice its longshore length, from one headland to the other. Although the studied beaches are characterized by diverse geological settings, 
176 Scott et al. (2011) found them to be similar with respect to beach type

177 and all beaches are considered Low-Tide Bar Rip (LTBR) beaches. The

178 similarity in beach state is explained by the similar hydrodynamic

179 conditions. All beaches are macrotidal, with the mean spring tidal

180 range decreasing from north (6.7 $\mathrm{m}$ at Widemouth \#1) to south (5.8

$181 \mathrm{~m}$ at Sennen \#10) (Table 1). The beaches also all have a similar SSW-

182 NNE orientation (Fig. 2 and Table 1) and are, therefore, exposed to

183 similar shore-normal wave conditions. The resulting cross-shore

184 exchange of sediment in response to changing wave conditions is

185 more significant than sediment redistribution alongshore (Buscombe

186 and Scott, 2008), as demonstrated by an analysis of the $2013 / 14$

187 storm response of all beaches in the southwest of England by Burvingt

188 et al. (2017).

$189 \quad$ Fig. 1 here

$190 \quad$ Fig. 2 here

191 Table 1 here

192 2.2. Topographic data

193 As part as the South West Coastal Monitoring Program, many

194 beaches along the coastline of SW England are surveyed every 6/12

195 months, and RTK-GPS data sets are provided by the Plymouth Coastal

196 Observatory (http://southwest.coastalmonitoring.org/). The study

197 sites were surveyed twice a year from 2007 to 2017 in spring season

198 (February-March-April) and autumn season (September-October-

199 November), except for Watergate \#5 and Gwithian \#9 beaches, which 

are generally surveyed at the same time of the year within a period of 2-3 months (Table 2 ) and because they are fairly dynamic, a difference of 3 months can make the inter-site comparison between beach changes potentially problematic. However, beach behaviour at these 10 study sites is also very seasonal, and the seasonal variations observed at the beach are more significant than the variations that occur over 2-3 months within the same season. The lag between surveys therefore accounts only for relatively small variations in beach changes and these are discussed later in sections 4.1 and 6 .

Table 2 here

Individual datasets consist of a site-specific number of 2D cross-shore profiles that were surveyed at the exact same location throughout the 10 years and that often stretch along the entire longshore length of the beach (Fig.2 and Table 1). The surveys are carried out during spring tides to maximise beach coverage and extend vertically from around mean low water spring level (MLWS) to the top of the backshore, or dunes when present. integrated for every cross-shore profile based on the shortest profile over the 10-year period (Equation 1).

$221 \quad V_{\text {profile }}=\int_{z_{\min }}^{z_{\max }} z d z$

222 where $z$ corresponds to the topographic values interpolated every metre, and $z_{\min }$ and $z_{\max }$ are the lowest and the fixed backshore 

computed for every survey to create a beach volume time series, $V$ in $\mathrm{m}^{3} \mathrm{~m}^{-1}$, relative to the first survey $(V($ Autumn 2007) $=0)$. Beaches are also represented by either one or several cross-shore profiles $(N)$ that are approximatively equally-spaced and spread over the entire beach (Figure 2). As these beaches are cross-shore dominated, the profile volume time series can be averaged to obtain longshore-averaged beach volume time series $V$ (Equation 2).

233 The cross-shore profiles stretching from $z_{\min }$ to $z_{\max }$ (fixed backshore 234 topographic) point were also vertically divided in two zones if dunes 235 are present, with the dunes area extending from the dune foot to the $236 Z_{\max }$ (Fig. 3). For the sediment volume computations, the distinction between the elevation of the top of the beach and the base of the dunes (the dune foot) was estimated by adding the vertical storm runup computed using Stockdon et al. (2006), for a typical beach gradient of 0.02 and average storm wave conditions characterised by $\mathrm{Hs}=5.2 \mathrm{~m}$ and $\mathrm{Tp}=11 \mathrm{~s}$, to the MHWS level. This storm runup elevation is $1.2 \mathrm{~m}$ and is representative of a storm event and was coherent with the few dune foot measurements present in the

244 dataset.

245 In the following sections, beach volume changes, $d V$ in $\mathrm{m}^{3} \mathrm{~m}^{-1}$, are used to express the longshore-averaged beach volume changes between surveys. Beach recovery from erosion, expressed as a \%, is defined as: 
$249 \quad$ Recovery $=100 * \frac{V_{\text {last }}-V_{\text {post }}}{V_{\text {pre }}-V_{\text {post }}}$

250 where $V_{\text {last }}$ is the profile for which the recovery is being computed,

251 and $V_{\text {pre }}$ and $V_{\text {post }}$ represent the beach volumes associated with pre-

252 and post-storm surveys, respectively.

$253 \quad$ Fig. 3 here

\subsection{Wave, tidal and climate index data}

Modelled wave data were obtained from the Met Office 8-km WAVEWATCH III model; data were validated by Saulter (2017). Threehourly values of significant wave height $H_{s}$ and peak wave period $T_{p}$ were extracted from 1 January 1980 to 31 December 2016 at a 50-m deep grid point located half-way along the study region (Fig. 1). This time-series was extended to 30 June 2017 using $H_{s}$ and $T_{p}$ values measured at a nearshore directional wave buoy located $1.4 \mathrm{~km}$ offshore of Perranporth beach in 16-m water depth deep $\left(50.35379^{\circ} \mathrm{N}, 5.17497^{\circ} \mathrm{W}\right.$, Fig. 1), deployed since December 2006 by the Channel Coastal Observatory. Least-squares regression between the measured (averaged every 3 hours) and modelled datasets for the period 2006-2016 reveals that the $H_{s}$ time-series are significantly correlated $(r=0.93, p=0.000)$, despite the fact that the model node

268 is located further offshore. There is more scatter in the $T_{p}$ time series

$269(r=0.84, p=0.000)$ (Fig. 4). The linear regression models obtained (refer to Fig. 4) were used to extend the modelled $H_{s}$ and $T_{p}$ time series to 30 June 2017 to maximise the overlap between wave forcing and beach profile observations. Wave directions measured at the 
273 Perranporth wave buoy were also used to produce the wave rose in

274 Fig. 1. Measured tidal water levels, from an Etrometa step gauge

275 deployed in July 2010 at Port Isaac (Fig. 1), were also provided by the

276 Channel Coastal Observatory. The WEPA winter index values from

2771980 to 2017 were provided by Bruno Castelle (University of

278 Bordeaux, France). This index was computed using the variations of

279 the sea level pressure gradient between the stations Valentia (Ireland)

280 and Santa Cruz de Tenerife (Canary Islands) located in the North

281 Atlantic Ocean (Castelle et al., 2017b). These variations were

282 averaged and normalized each year over the months of December,

283 January, February and March (Boreal winter) to obtain the time-

284 series presented in Figure 5c.

$286 \quad$ Fig.4 here

\subsection{ShoreFor model}

288 To test whether any coherent responses between the study sites are

289 coherently related to the offshore wave forcing, and importantly

290 whether this variability is potentially predictable, observations are

291 compared with a subtle variant of the equilibrium shoreline ShoreFor

292 model proposed by Davidson et al. (2013). This variant predicts beach

293 volume variability rather than shoreline change, the results proposed

294 in this study are thus comparable with other recent studies using

295 beach volume changes to describe the 2013/14 storm response

296 (Castelle et al., 2015; Masselink et al., 2016; Scott et al., 2016) and no

297 significant differences should be observed in terms of model 
predictions. This equilibrium model is based upon the principle that cross-shore-dominated shorelines migrate toward a time-varying equilibrium position (Wright et al., 1985). Here we give a very brief description of the model and the reader is referred to Davidson et al., (2013) for a more detailed description of the model.

The change in beach volume per metre coastline, $d V$, with time is computed using Equation 4 where $P$ is the incident wave power expressed in $\mathrm{W}, \mathrm{c}$ is a rate parameter expressed in $\mathrm{m}^{2.5} \mathrm{~s}^{-1} \mathrm{~W}^{-0.5}$, and $\Omega$ is the dimensionless fall velocity which is a simple function of local wave conditions and sediment grain size $\left(\Omega=H_{b} / w T_{p}\right.$ where $H_{b}$ is the significant breaking wave height, $w$ is the settling velocity, and $T_{p}$ is the spectral peak wave period).

$310 \quad \frac{d V}{d t}=c P^{0.5}\left(\Omega_{\phi}-\Omega\right)$

311 The first model free parameter, $c$, controls the magnitude of the

312 volume change and is optimized by direct comparison between the

313 model prediction and observations, while the use of a temporally

314 varying equilibrium condition $\Omega_{\phi}$, which is based on a weighted

315 average of the antecedent dimensionless fall velocity over a time-

316 scale $\phi$, describes the "memory" of a beach to antecedent conditions.

317 The second model free parameter, $\phi$, is called the response factor

318 and it controls the window-width (in days) of the weighted

319 antecedent average. This weighting function has a centre of mass at

$3200.41 \phi$, thus seasonal variation have $\phi$-values of order $10^{3}$ days, whilst

321 more storm dominated site are characterised by $\phi$-values $<10^{2}$ days. 
322 The numerical tests on ShoreFor by Splinter et al. (2013) suggested

323

324

325

326

327

328 that bi-annual measurements of coastal change utilised in the present paper would not be of sufficient temporal resolution to adequately optimise the second model free parameter, $\phi$. Thus, here we use the parameterisation proposed by Splinter et al. (2014), to compute an appropriate value of $\phi$, based only on the knowledge of the observed sediment characteristics and wave climate. Based on an average grain size value of $0.37 \mathrm{~mm}$, the Splinter et al., (2014) parameterisation yielded a value for $\phi \approx 1000$ days, which typifies environments with a strong seasonal variability.

The ShoreFor model has been shown to have high skill at forecasting coastal recession and progradation on exposed energetic coastlines dominated by cross-shore sediment transport (Davidson et. al, 2013; Splinter et al., 2014; Davidson et al., 2017); however, it takes no account of the longshore sediment transport process. For the current study sites, this model restriction is not thought to be particularly severe since sediment transport at the 10 beaches is dominated by cross-shore processes (Buscombe and Scott, 2008; Burvingt et al., 2017).

\section{Wave forcing}

\subsection{Multi-annual wave conditions time-series}

The time series of modelled significant wave height $H_{s}$, peak energy period $T_{p}$ and winter WEPA index from 1980 to 2016 are presented in

Fig. 5. The 8-week block-averaged $H_{s}$ and $T_{p}$ time series clearly 
highlight the seasonal variability in wave conditions between winter and summer. Over the last 36 years, six very energetic winters can be observed from the $H_{s}$ time series (Fig. $5 a$ and 5b). The 'Great Storm' of 1987 and the 'Burn's Day Storm' in 1990 were reported (McCallum, 1990) for the strength of wind gusts recorded, and caused widespread damage and the dramatic loss of 18 and 47 lives in the UK, respectively. Three years later, the 'Braer Storm' of 1993 had one of the lowest-ever recorded central pressures $(914 \mathrm{mb})$ in the North Atlantic (McCallum and Grahame, 1993; Burt, 1993) and the 1994/95 winter was reported as 'very cyclonic' (Hulme, 1997). More recently, the $2013 / 14$ winter wave conditions associated with storms were the most energetic since at least 1948 along the southwest coast of England (Masselink et al., 2015), followed by the 2015/16 winter that was as energetic as 1993 and 1994/95 mentioned previously (Fig. 5a).

The winter WEPA time-series show that the high $H_{s}$ values during the 1993/94, 1994/95, 2013/2014 and 2015/2016 winters are all synchronous with positive peaks along the winter WEPA index timeseries (Fig. 5c). However, only average wave conditions occurred during the 2001 winter when WEPA was strongly positive. The relationship between the winter-mean significant wave height $H_{s}$ and the winter WEPA index was analysed and showed that the two timeseries were strongly correlated over the 1980-2017 and the 10-year (Fig. 6). 
372 Based on the 6-monthly topographic surveys carried out around

373 spring and autumn months, and the monthly-averaged wave

374 conditions $\left(H_{s}\right.$ and $\left.T_{p}\right)$ presented in Fig. 1 , each year is divided into a

375 winter and summer season spanning the 6 months between October-

376 March (ONDJFM), and April-September (AMJJAS), respectively. The

377 addition of October and November to the Boreal winter (December,

378 January, February, March), used to calculate winter WEPA index

379 values, did not alter the relationship between winter WEPA index and

380 winter-mean significant wave height over the study period, which

381 show an even better correlation coefficient $(r=0.84, p=0.000)$. Over

382 the 2007-2017 period, for which RTK-GPS survey data are available,

$383 H_{s}$ and $T_{p}$ winter-mean values ranged from $1.80 \mathrm{~m}$ to $2.73 \mathrm{~m}$, and 10.6

$384 \mathrm{~s}$ to $11.9 \mathrm{~s}$, respectively (Table 3), with the highest winter-mean

385 values exceeding $2.5 \mathrm{~m}$ and $11 \mathrm{~s}$ during the 2013/14 and 2015/16

386 winters. Summers are characterized by lower $H_{s}$ and $T_{p}$ mean values,

387 ranging from 1.30 to $1.54 \mathrm{~m}$ and 8.6 to $9.1 \mathrm{~s}$ (Table 4), respectively,

388 with the least energetic months corresponding to the 2014 summer

389 (1.18 $\mathrm{m}$ and $8.8 \mathrm{~s})$. As observed in Fig. $5, H_{s}$ and $T_{p}$ values also show a

390 strong seasonal signal, in addition to inter-annual variability.

$391 \quad$ Tables 3 and 4 here

\subsection{Multi-annual storminess}

The peaks-over-threshold (POT) method is commonly used to identify coastal storms from significant wave height time series (Houser and 

identified three parameters to specify when using the POT method:

(1) the storm threshold; (2) the minimum storm duration; and (3) the meteorological independence criterion. Based on the time series of modelled significant wave height $H_{s}$ and similarly to Masselink et al. (2015), a storm is defined here as a wave event during which the maximum $H_{s}$ exceeds the $1 \%$ exceedance offshore wave height (5.2 m), and where the start and the end of the storm event is when $H_{s}$ exceeds or falls below the $5 \%$ exceedance wave height $(3.8 \mathrm{~m})$. These wave exceedance values were calculated using the modelled $H_{s}$ wave time-series over the last 10 years only, to avoid the influence of longterm trends in winter-mean wave height (Castelle et al., in prep). Given that the southwest coast of England is mostly exposed to extratropical storms, a meteorological independence criterion of 24 hours is used to distinguish storm events, as suggested by Ciavola and Coco (2017). The numbers of storm events during winter and summer months from 2006 to 2016 are reported in Table 3 and 4 . The number of storms shows a high seasonal variability and only three of the 76 storm events identified between October 2006 and June 2017 occurred during summer months (Table 3 and 4). The highest number of storm events are associated with the $2013 / 14$ and 2015 /16 winters

417 (17 and 12 storms, respectively) while only one storm occurred during 418 the 2016/17 winter, representing the lowest number among the last 41910 years (Table 3 and Fig. 7). The number of winter storms varies from one year to another, ranging from 1 to 17 over the 10 -year study 
421 period. Mean storm durations are also highly variable from one

422 winter to another, ranging from 5 to 18 hours (Table 3), justifying the

423 use of an independence meteorological criterion of 24 hours.

424 Although the role of storm surge is limited and rarely exceeds $1 \mathrm{~m}$

425 along this open coast (Masselink et al., 2015), the coincidence of the

426 peak storm with spring tides has a particular importance since 5 of

427 the macro-tidal study sites have a supra-tidal dune system (Table 1).

428 During the 2013/14 winter, for the 17 storms recorded, 7 storms

429 occurred at approximatively the highest stage of the spring tides,

430 while 6 of the 12 storms occurred at that stage during the 2015/16

431 winter (Fig. 7).

432 Fig. 7 here

433 4. Regionally coherent beach behaviour, storm

434 response and recovery

435 4.1. Influence of wave forcing in beach behaviour

436 In the previous section, results showed that the 10 study sites were

437 exposed to temporally-varying seasonal wave conditions over the last

43810 years. The 6-monthly or yearly topographic changes in response to

439 this variability in wave forcing can be observed along individual RTK-

440 GPS beach profiles (Fig. 8). Observations at Constantine \#2, Trenance

$441 \quad \# 4$ and Fistral \#7, used as three representative examples for all study

442 sites, showed that beach response is temporally and spatially

443 coherent. Overall, few morphological changes were observed at the

444 three representative study sites over the 2011/12 winter while beach 
446 the 2016 summer, respectively (Fig. 8). However, the magnitude of

447 the morphological changes differs from one site to another. All beach

448 profiles surveyed over the last 10 years are bounded by the Autumn

4492013 and Spring 2014 profiles, suggesting that the 2013/14 winter

450 corresponds to the most erosive event for at least 10 years, and the

451 three beach profiles corresponding to Autumn 2016 suggest that

452 beach recovery from that winter was not complete 2.5 years later (Fig.

453 8).

$454 \quad$ Fig. 8 here

455 To capture and study the temporal volume changes observed along

456 these cross-shore profiles, the longshore-averaged beach volume

457 time-series, $V$, were computed from 2007 to 2017, using the

458 methodology presented in section 2.2 (Equation 2). All the 10

459 longshore-averaged beach volume time-series over the last 10 years,

460 presented in Fig. 9, showed that: (1) beaches presented a seasonal

461 behaviour with most winters characterised by erosion while most

462 summers were associated with accretion; and (2) beaches showed a

463 coherent behaviour, although volume change magnitude can differ

464 (Fig. 9). These differences in magnitude can be partly explained by the

465 differences in beach characteristics, and also by the different dates at

466 which beaches were surveyed, as mentioned in section 2.2.

$467 \quad$ Fig. 9 here 
When considering the average of the 10 beach volume time-series, $V_{\text {avg, }}$ and its bounded standard deviation, representing inter-site variability, four different phases can be identified (Fig. 10a). During the first phase, from autumn 2007 to autumn 2010, the 10 beaches accreted with an average rate of volume change of $3.6 \mathrm{~m}^{3} \mathrm{~m}^{-1}$ per month (Fig. 10a). During this phase, winter periods were ranked as $5^{\text {th }}$, $7^{\text {th }}$ and $9^{\text {th }}$ most energetic and corresponded to the recovery phase following the energetic $2006 / 07$ winter ranked as the $3^{\text {rd }}$ most energetic over the last 10 years (Table 3). Accordingly, the yearly

477 WEPA index gradually decreased from 0.5 to -1.25 during this 3-year 478 phase (Fig. 10c). The second phase, spanning the three years between 479 autumn 2010 and autumn 2013, was characterized by an equilibrium in beach volume change $\left(-7 \mathrm{~m}^{3} \mathrm{~m}^{-1}\right)$ where seasonal sediment exchange was dominant over inter-annual exchange (Fig. 9). This suggests that the beaches reached an equilibrium as recovery from the $2006 / 07$ winter was complete. This phase was associated with a relatively stable WEPA index from 2010 to 2012 followed by a rapid increase from -1.20 to 1 during 2013 which did not seem to influence the volume changes (Fig. 10c). Phase 3, corresponding to the 2013/14 winter, was the strongest erosive event over the last 10 years as previously observed along the three cross-shore profiles in Fig. 8. Between autumn 2013 and spring 2014, the 10 beaches lost from 80 to $384 \mathrm{~m}^{3} \mathrm{~m}^{-1}$ (Fig. 9), resulting in an average erosion rate of $34 \mathrm{~m}^{3} \mathrm{~m}^{-}$

$491{ }^{1}$ per month. These large losses of sand occurred during the most energetic winter of the study period (Fig. 10b), where 17 storms were recorded (Fig. 7a and Table 3), associated to the WEPA index 10-year 

values between 2013 and 2014 is similar to the increase observed between 2012 and 2013, the wave conditions and associated beach responses were much stronger, suggesting a threshold effect in the WEPA control on wave climate. Phase 4, which corresponded to the following three years from spring 2014 to spring 2017, was related to the recovery period from the extreme storms of phase 3 . From spring 2014 to autumn 2015, the beaches slowly recovered with an average accretion rate of $3.5 \mathrm{~m}^{3} \mathrm{~m}^{-1}$ per month (Fig. 10a). The smaller wave conditions during the $2014 / 15$ winter compared to the $2013 / 14$ winter (Fig. 7a and 7b) were associated with a decrease of the WEPA index through 2015 (Fig. 10b and 10c). However, that winter was still relatively energetic (ranked $4^{\text {th }}$, Table 3 ) and resulted in variable response among the 10 study sites with both erosion or accretion depending on the beach (Fig. 9). Most of the sand recovered over this 1.5 years was lost during the energetic 2015/16 winter (Fig. 7c), which ranked as the second most energetic period over the last 10 years (Table 3) and paired with the second highest value of WEPA index (Fig. 10c), adding to the hypothesis of a threshold effect observed in phase 3. These losses were quickly recovered the next summer in 2016 (Fig.

514 10a), and accretion ( $36 \mathrm{~m}^{3} \mathrm{~m}^{-1}$ ) even occurred during the $2016 / 17$

515 winter when calm wave conditions prevailed and no storms occurred

516 (Fig. 7c and 10b). This winter also had a reduced WEPA index (Fig. 10c).

517 When considering the volumes lost between spring 2013 and spring 5182014 , these losses were recovered on average by 77\% in spring 2017. However, recovery percentages were highly variable between the 10 

deviation along the average volume time-series during phase 4 (Fig. 10a).

524 The volume changes observed during the 3-year recovery period 525 (phase 4) suggested that summer conditions contribute to beach 526 recovery but, above all, the recovery trajectory is largely and mainly 527 forced by winter waves. The mean of the 6-monthly volume changes, $528 d V_{\text {mean }}$ over winter and summer months, and the associated 6529 monthly significant wave height, $H_{s}$, were therefore computed and 530 compared. Results showed that both volume changes and wave 531 conditions during summer months represent rather small inter532 annual variability compared to winter months (Fig. 11). For example, the $58 \mathrm{~m}^{3} \mathrm{~m}^{-1}$ gained during the 2015 summer was rapidly lost during the subsequent energetic winter $\left(-97 \mathrm{~m}^{3} \mathrm{~m}^{-1}\right)$ while the $96 \mathrm{~m}^{3} \mathrm{~m}^{-1}$ gained during the 2016 summer were supplemented by the

536 subsequent calm winter $\left(+36 \mathrm{~m}^{3} \mathrm{~m}^{-1}\right)$. Results also showed that inter537 site variability in volume change, represented by the error bars, was 538 larger during winter months than summer months over the study 539 period, especially when wave conditions were energetic (Fig. 11). The 54010 beaches average standard deviation of 6-monthly volume changes

541 from 2007 to $2017, d V_{\text {std, }}$, which represents the inter-site variability in

542 volume change, was therefore computed and plotted against the 543 corresponding 6-monthly significant wave height mean values (Fig.

544 12). Over winter months, the increase of deviation in volume changes 
545 between the 10 study sites was strongly correlated with the increase

546 of significant wave height $(r=0.83)$, while no significant correlation

547 was found between these two variables over summer months (Fig.

$54812)$

\section{$549 \quad$ Fig. 11 here}

\section{Fig. 12 here}

551 The longshore-averaged beach volume time-series showed that the

55210 study sites located along the north coast of Cornwall presented a

553 coherent and synchronous behaviour from 2007 to 2017. For each

554 beach, the volume changes were partly controlled by intra-annual

555 variability due to the strongly seasonal wave climate, but largely

556 controlled by the inter-annual variability in wave forcing during

557 winter months, especially when sequences of extreme storms were

558 recorded. This variability in winter wave forcing was also shown to

559 create some variability in volume change between study sites and to

560 have a large influence on recovery processes. Furthermore, the

561 average of the 10 beach volume time-series was shown to be fairly

562 well correlated with North Atlantic climate variations illustrated by

563 the yearly WEPA index, although similar variations in WEPA index

564 values were not associated with the same beach response, suggesting

565 the existence of a threshold in WEPA control or the influence of other

566 processes.

567 4.2. Influence of geomorphological and geological boundaries

568 in beach behaviour 
In the previous section, the 10 beaches showed a coherent and synchronous behaviour over the last 10 years. However, some variability in the magnitude of volume change was observed between the 10 study sites, which increased when waves become more energetic. Accordingly, the percentages of sand volume recovered following the extreme events of the $2013 / 14$ winter highly varied between the 10 beaches. This variability could be partly explained by small differences in coastline orientation that influence inshore wave conditions, which were not addressed here because a generalised offshore wave forcing was used for all study sites, rather than a beach-specific inshore wave forcing. It could also be explained by other intrinsic beach characteristics that vary between the 10 study sites (Table 1). The influence of dune systems on multi-annual beach behaviour is investigated here.

In the present study, five sites have dune systems that vary in alongshore extent (from 160 to $2400 \mathrm{~m}$ ) and height (from 11 to $22 \mathrm{~m}$ ). The role of storm surge is limited along the open coast of North Cornwall, and rarely exceeds $1 \mathrm{~m}$ (Masselink et al., 2015); however, the coincidence of events of energetic and long-period waves with spring high tides can induce strong dune erosion. The influence of coastal dune systems on beach volumetric changes over the last 10 years was investigated by quantifying the longshore-averaged dune volume time series, as mentioned in section 2 . The volume time series associated with the dunes, $V_{\text {dunes }}$, at Widemouth $\# 1$, Constantine $\# 2$, variably active over the last 10 years (Fig. 13). The contribution of 

dune volume changes over intertidal beach volume changes was highly variable between the different study sites, being either insignificant at Widemouth \#1, small at Constantine \#2, Gwithian \#9 and Sennen \#10, or significant at Porthcothan \#3. Being relatively stable during phases 1 and 2, larger dune volume changes are observed during the third and fourth phases (Fig. 13). The largest losses of dune sand were observed during the 2013/14 winter at Constantine \#2, Porthcothan \#3, Gwithian \#9 and Sennen \#10 (-48, $40,-35$, and $-23 \mathrm{~m}^{3} \mathrm{~m}^{-1}$, respectively), while very little volume change was observed at Widemouth \#1 $\left(-9 \mathrm{~m}^{3} \mathrm{~m}^{-1}\right)$. The 2015/16 winter was also responsible for strong and significant dune erosion at 606 Porthcothan \#3 and Sennen \#10 (-41 and $-16 \mathrm{~m}^{3} \mathrm{~m}^{-1}$, respectively). Moreover, the cross-shore RTK-GPS profiles showed that the way dunes eroded was also variable between study sites. At Constantine $\# 2$, and Sennen \#10, which have relatively steep and high dunes, sand was mostly eroded from the fore dunes or/and the toe of the dunes during the 2013/14 winter, while much larger dune scarping and steepening was observed at Porthcothan \#3 (Fig. 13). Cross-shore RTK-GPS profiles of the dunes at Widemouth \#1 and Gwithian \#9 was not presented here because no significant dune erosion was observed at Widemouth and only yearly beach profiles are available at 616 Gwithian. The rate of dune recovery between these study sites was 617 also site-specific; between their pre-storm state in spring 2013 and 618 spring 2017, dunes completely recovered (Constantine \#2), partly recovered (Gwithian \#9 and Sennen \#10) or remained in an erosive state (Porthcothan \#3). 
622 Dune systems can therefore represent a source of temporal and

623 spatial variability when comparing the magnitude of volume change

624 from one site to another. Over the last 10 years, dunes along the

625 north coast of Cornwall were only significantly impacted during the

$6262013 / 14$ winter, and were likely to be one of the factors that

627 contributed to the increase of inter-site variability in volume change

628 during that period. Furthermore, some variability in the way dunes

629 responded to the 2013/14 extreme storms was also observed

630 between the 5 sites that have dunes, which consequently influenced

631 storm response and beach recovery over the whole beach system.

\section{5. Modelling of multi-annual beach behaviour}

633 In the previous section, the longshore-averaged beach volume time

634 series was strongly controlled by seasonal and inter-annual wave

635 forcing. The 6-monthly volume changes, $d V$, for each study site were

636 plotted against the corresponding 6-monthly significant wave height

637 mean values $H_{s \text { mean, }}$ and the 6-monthly cumulative storm duration

638 (Fig. 14). Trends of decrease in beach sand volumes with increase in

639 wave height (Fig. 14a) and storm duration (Fig. 14b) can be observed.

640 Despite the presence of some inter-site variability, a threshold

641 between accretion and erosion can be observed within a range of

642 mean significant wave height from 1.6 to $1.7 \mathrm{~m}$, while most of the

643 study sites were subject to erosion when cumulative storm wave

644 conditions exceeded 13 hours. These threshold values correspond

645 roughly to an energetic summer and a calm winter, when considering 
646 the seasonal wave conditions of the last 10 years. Furthermore,

647 erosion was systematically observed when waves exceed $2.5 \mathrm{~m}$ and

648 the cumulative storm duration exceeds 100 hours (Fig. 14).

\section{Fig. 14 here}

650 The trends between volume changes and wave forcing storms

651 depicted in Figure 14 do not take into account antecedent wave

652 conditions, while previous results suggested that they have a

653 significant role in beach behaviour. For this purpose, the ShoreFor

654 model was used to explore in more detail the relationship between

655 wave forcing and beach response. Considering the largely coherent

656 beach behaviour dominated by cross-shore sediment transport

657 across the study region, the time series representing the average

658 beach volume time series for the 10 beaches was used (Fig. 15).

659 Fig. 15 here

660 Pearson's correlation coefficient, R, and the Brier Skill Score, BSS

661 (Sutherland et al., 2004) calculations suggested that the model

662 provides a good hindcast of the average of the 10 beach volume time-

663 series ( $r=0.85$ and BSS $=0.71$, respectively). In general, the model

664 predicts quite well both the seasonal and inter-annual variability in

665 volume change. While apparent overestimations of the eroded

666 volumes can be observed in phase 1 and 2 (e.g. 2007/08 winter,

$6672009 / 10$ winter, 2011/12 winter), the erosive impact of the extreme

668 2013/14 storms (phase 3) is slightly under-estimated, and the

669 recovery during the following 6 months (Summer 2014) is largely 

over-estimated if the previous underestimation is not considered (Fig.

671 15). The increase of inter-site variability in the magnitude of volume

672 change over that period partially dilutes the skill of the model. Indeed,

673 less accretion occurred during the 2014 summer at most of the study

674 sites than the model suggests. Because most of the beaches were still

675 in a very-much depleted state by the end of the 2014 summer, the

676 2014/15 winter was accretionary. The ShoreFor model predicts

677 erosion during the $2014 / 15$ winter because of the over-prediction for

678 the accretion during the preceding summer. However, the energetic

$6792015 / 16$ winter storm response and its subsequent recovery was very

680 well captured by the model. The good ShoreFor model results

681 demonstrate that the observed coherent regional variability in sand

682 volume is linked to incident wave forcing. Consideration of

683 antecedent conditions through their inclusion in the model also

684 demonstrates the importance of antecedent conditions on future

685 volume change in comparison to the simple correlations with

686 significant wave height (Fig. 14).

687 In the previous section, the average of the 10 beach volume time-

688 series was shown to be fairly well correlated with North Atlantic

689 climate variations illustrated by the WEPA index (Fig. 10). Based on

690 these results, winter volume changes, $d V$, for each study site were

691 plotted against values of the winter WEPA index (Fig. 16a). Results

692 showed that these two variables were well and negatively correlated

$693(r=-0.78)$ over the last 10 years. Similarly, modelled winter volume

694 changes obtained using ShoreFor were plotted against values of the

695 winter WEPA index (Fig. 16b), and also showed a good correlation ( $r$ 
$696=-0.80)$. Although the thin line between an accretive and an erosive

697 winter was difficult to observe within the variability in WEPA index

698 values, these negative correlations were particularly verified for the

699 extreme values of the datasets (e.g. 2013/14 and 2015/16 winters),

700 implying the use of strong positive WEPA index values as extremely

701 energetic winters and a possible threshold effect as mentioned in

702 section 4 . Since our volume time series were shown to be mainly

703 shaped by the temporal occurrence of these extreme events, these

704 results suggest that the WEPA index values and the ShoreFor model

705 predictions could be used as proxies for wave conditions and

706 measured beach volume changes, respectively, in studies focusing on

707 beach dynamics over multi-annual timescales.

708 Fig. 16 here

\section{6. Discussion}

710 From 2007 to 2017, the north coast of Cornwall experienced highly

711 variable wave conditions on seasonal and inter-annual temporal

712 scales. This variability in wave conditions, which was fairly well

713 correlated to a new climate index proposed for the Atlantic coast of

714 Europe (WEPA; Castelle et al., 2017b), drove a synchronous and

715 coherent beach response, dominated by cross-shore sediment

716 transport, for the 10 studied beaches along this coastline. Such

717 regionally-coherent coastal response has also been demonstrated for

718 the east coast of Australia, where it was found that beaches of similar

719 orientation had synchronous oscillation and rotation over a 6-year

720 period (Short et al., 2014; Bracs et al., 2016). However, the three 
beaches along the east coast of Australia have similar size while, here, the 10 study sites represent a wide variety of beach size and length. As also observed for Perranporth beach (Poate et al., 2014; Masselink et al., 2016 ; Scott et al., 2016), a well-studied beach located along the north coast of Cornwall not included in the present data set, beach volume time series of all 10 studied beaches showed seasonal variations superimposed on inter-annual variations coupled to winter wave activity. Such multi-scale variation in wave conditions is generally observed on storm-dominated coastlines with a seasonal wave climate (Ruggiero et al., 2005; Pye and Blott, 2008; Castelle et al., 2015; Barnard et al., 2017; Harley et al., 2017a).

The 10 -year study period includes the $2013 / 14$ winter, which was the most energetic winter since, at least, 1948 and caused significant morphological changes all along the west coast of Europe (Masselink et al., 2016). Results showed that these extreme wave conditions to which our 10 study sites were fully exposed (Burvingt et al., 2017), were responsible of the most erosive event over, at least, the last decade. The antecedent morphological beach state being a controlling factor of beach response to storm (Voudoskas et al., 2012; Harley et al., 2016), the dramatic response of the beaches to the $2013 / 14$ winter is partly attributed to the fact that the beaches were in their most accreted state after the 2013 summer, enhancing the disequilibrium between beach state and wave forcing during the 2013/14 winter. Furthermore, these extreme events drove an increase of variability in the magnitude of volume change between 

cross-shore profiles were surveyed vary from one beach to another. A late winter survey could possibly not include one or several storms, while a late spring survey would and could even capture some of the recovery processes. This issue has, however, only minor consequences on the results since seasonal variations in beach volume change are much larger than the changes measured by 2 month-spaced surveys carried out within the same season. Second, the 10 study sites present different geological settings. Beach morphological response to storms was demonstrated to be strongly controlled by local coastline orientation relative to storm wave direction (Burvingt et al., 2017; Harley et al., 2017a). The small differences in coastline orientation among our study sites, resulting in differences in inshore storm wave conditions, not accounted for here, could have been enhanced during storm conditions and may explain the increase of variability in volume change magnitude among the 10 beaches following the 2013/14 winter. Moreover, this study also showed that, after being relatively stable from 2007 to 2013, dunes shifted from swash to collision regime (Sallenger, 2000) during the 2013/14 winter, highlighting the episodic and irregular nature of beach-dune interactions (Pye and Blott, 2008; Castelle et al., 2015). The spatial variability of dune response to storm waves can be

769 accounted for by the increased variability in volume change 770 magnitude among the 10 beaches; likewise, other intrinsic beach 771 characteristics could also have played a role, such as sediment size and availability (Prodger et al., 2016), headland by-passing (Burvingt 

presence of large rocky platforms.

Three years after the 2013/14 extreme storms, beach recovery is variable (from 5 to 200\%) between study sites covering the four beach recovery stages defined by Morton et al. (1994). Recent studies have also shown that substantial beach recovery following storm events can occur after days (Angnuureng et al., 2017) or between one and two years (Castelle et al., 2017a; Harley et al., 2017b). In our 10beach dataset, only six beaches showed a percentage of recovery close or superior to $100 \%$ after 3 years, while four beaches are still recovering (between 5 and 70\%). The belated post-storm beach recovery along the north coast of Cornwall appears to be mainly controlled by the winter wave conditions over the years following extreme storms, with the wave height variability in summer only playing a minor role. Indeed, only one energetic winter, such as the 2015/16 winter, nullified the total recovery that occurred over the previous 18 months. Summer conditions consistently contribute to modest beach recovery, but substantial recovery over a year only takes place when a mild and therefore accretionary winter occurs. Over the 10-year study period, the 2008/09, 2014/15 and 2016/17 winters were all accretionary and they also followed intense erosive periods during the 2006/07, 2013/14 and 2015/16 winters that left the beaches in a depleted state. These results re-emphasise the importance of the antecedent wave conditions, as well as the actual wave forcing in driving beach response. It should be noted that this conclusion concerning beach recovery is valid only for beaches with 
prevailing cross-shore sediment transport; recovery of beaches dominated by longshore sediment transport processes (Scott et al., 2016; Burvingt et al., 2017) is not simply dictated by the difference between antecedent and actual wave steepness, and requires a consideration of the wave direction.

Building on the coherent and synchronous beach behaviour at all study sites and the strong correlation between wave forcing and beach response, the ShoreFor equilibrium model (Davidson et al., 2013) was used to hindcast the average beach volume time series taking into account all 10 beaches. The good skill of the model indicates that the observed regionally-coherent variability in sand volume is linked to incident wave forcing and is, importantly,

811 potentially predictable. Consideration of antecedent conditions

812 through their inclusion in the model improves the skill of predictions,

813 highlighting the importance of antecedent conditions on future beach

814 volume/shoreline change, as demonstrated in previous field studies

815 (Wright et al., 1985; Plant et al., 1999; Miller and Dean, 2004) and

816 applications of the model to other exposed sites (Splinter et al., 2014).

817 In agreement with the results of Splinter et al. (2014), application of

818 the ShoreFor model to the average beach volume time series for the

81910 Cornish beaches yields a response factor $\phi \approx 1000$ days. This

820 illustrates the strong seasonal signal with larger-winter (small-

821 summer) waves driving beach erosion (accretion) superimposed on

822 inter-annual variability in winter wave height driving extreme storm-

823 erosion during energetic winters and stability, or even recovery,

824 during mild winters. These results also show that the ShoreFor model 
explains most of the variability in 10 beaches when only modelled wave data were provided to force the model; this reinforces the conclusion that coherent behaviour is mainly controlled by offshore wave climate and is highly sensitive to the antecedent conditions, while beach intrinsic factors only act as secondary control factors. These findings illustrate that in regions with coherent coastal

831 response, a relatively simple shoreline model based on the difference

832 between actual wave conditions and the equilibrium conditions can

833 be successfully applied for the whole region. This has further

834 implications for the management of beaches in terms of both

835 predicting the impact of storms and assessing potential rates of beach

836 recovery following severe erosion (Davidson et al., 2017). Moreover,

837 the significant correlations between the climate index controlling

838 winter wave activity along the Atlantic coast of Europe (WEPA)

839 especially during very energetic winters, and observed/modelled

840 beach annual volume changes is a promising result for the

841 development of weather regime-driven beach/shoreline models, as

842 suggested by Robinet et al. (2016). The recent skilful predictability of

843 the winter North Atlantic Oscillation (Dunstone et al., 2016), which is

844 the primary mode of atmospheric variability in the North Atlantic

845 region, and its implication on coastline change along the western

846 coast of Europe is worthwhile exploring.

\section{7. Conclusions}

848 1. Regionally-coherent and synchronous behaviour over the decadal

849 time scale was observed at 10 cross-shore dominated and energetic 

beaches exposed to similar wave conditions, but having different sediment characteristics, beach lengths and degrees of embaymentisation. Some inter-site variability in the magnitude of volume change was observed and was shown to increase with winter significant wave height.

2. The sequence of extreme storms during the $2013 / 14$ winter corresponded to the most erosive event over, at least, the last 10 years along the southwest coast of England. Three years later, $60 \%$ of the beaches fully or over-recovered, while the remaining $40 \%$ only showed partial or almost non-existent recovery. Many factors accounted for this inter-site variability, such as the variability in dune erosion and recovery. Despite this spatial variability, beach recovery was shown to be mainly controlled by winter wave conditions over the years following extreme storms, in comparison to summer wave conditions that consistently contribute to modest beach recovery. obtained using an equilibrium-type shoreline model (ShoreFor), demonstrating that beach changes are coherently linked to changes in the offshore wave climate and highly sensitive to the antecedent

869 conditions. This finding also illustrates that, in regions with cross870 shore dominated beaches and coherent coastal response, the 871 ShoreFor model can successfully be applied for the whole region.

872 4. Over the last 10 years, good correlations were also found between

873 winter beach volume changes and climate index values controlling 874 winter wave activity along the Atlantic coast of Europe (WEPA), 
opening up the opportunity for the development of weather regimedriven beach/shoreline models.

\section{Acknowledgments}

879 This research was funded by NERC grants NE/M004996/1 (Urgency 880 Grant) and NE/N015525/1 (Strategic Highlights Topic grant). The 881 authors would like to thank Bruno Castelle, the Plymouth Coastal 882 Observatory team and the UK Met Office (Dr Andy Saulter), for kindly 883 providing the supporting WEPA index values, RTK-GPS data and the 884 modelled wave data, respectively. Marine Geology Editor Edward 885 Anthony, and anonymous reviewers are gratefully acknowledged for 886 their constructive comments that improved the manuscript.

\section{References}

Almeida, L.P., Vousdoukas, M.V., Ferreira, O., Rodrigues, B.A.,

Matias, A., 2012. Thresholds for storm impacts on an exposed sandy coastal area in southern Portugal. Geomorphology 143-144, 3-12. Marieu, V., Ranasinghe, R., 2017. Shoreline resilience to individual storms and storm clusters on a meso-macrotidal barred beach. Geomorphology 290, 265-276. 
898

899

900

901

902

903

904

905

906

907

908

909

910

911

912

913

914

915

916

917

918

919

920

921

Heathfield, D.K., 2015. Coastal vulnerability across the Pacific dominated by El Nino/Southern Oscillation. Nat. Commun. 8, 801808.

Barnard, P.L., Hoover, D., Hubbard, D.M., Snyder, A., Ludka, B.C., Allan, J., Kaminsky, G.M., Ruggiero, P., Gallien, T.W., Gabel, L., McCandless, D., Weiner, H.M., Cohn, N., Anderson, D.L., Serafin, K.A., 2017. Extreme oceanographic forcing and coastal response due to the 2015-2016 El Nino. Nat. Commun. 8, 14365.

Birkemeier, W.A., 1979. The effects of the 19 December 1977 coastal storm on beaches in North Carolina and New Jersey. Shore Beach 47, 7-15.

Bracs, M.A., Turner, I.L., Splinter, K.D., Short, A.D., Mortlock, T.R., 2016. Synchronised patterns of erosion and deposition observed at two beaches. Mar. Geol. 380, 196-204.

Bramato, S., Ortega-Sanchez, M., Mans, C., Losada, M.A., 2012. Natural Recovery of a Mixed Sand and Gravel Beach after a Sequence of a Short Duration Storm and Moderate Sea States. J. Coast. Res. 28 (1), 89-101.

Bromirski, P.D., Cayan, D.R., 2015. Wave power variability and trends across the North Atlantic influenced by decadal climate patterns. J. Geophys. Res. Oceans 120, 3419-3443.

Brooks, S.M., Spencer, T., Christie, E.K., 2017. Storm impacts and shoreline recovery: Mechanisms and controls in the southern North Sea. Geomorphology 283, 48-60. 
Burt, S., 1993. Another new North Atlantic low pressure record.

923

Weather 48 (4), 98-103.

924 Burvingt, O., Masselink, G., Russell, P., Scott, T., 2017. Classification

925 of beach response to extreme storms. Geormophology 295, 722-

926737.

927 Buscombe, D.D., Scott, T.M., 2008. The Coastal Geomorphology of

928 North Cornwall: St. Ives Head to Trevose Head. Wave Hub Impact on

929 Seabed and Shoreline Processes (WHISSP). University of Plymouth.

930 Castelle, B., Marieu, V., Bujan, S., Splinter, K.D., Robinet, A.,

931 Sénéchal, N., Ferreira, S., 2015. Impact of the winter 2013-2014

932 series of severe Western Europe storms on a double-barred sandy

933 coast: beach and dune erosion and megacusp embayments.

934 Geomorphology 238, 135-148.

935 Castelle, B., Bujan, S., Ferreira, S., Dodet, G., 2017a. Foredune

936 morphological changes and beach recovery from the extreme

937 2013/2014 winter at a high-energy sandy coast. Mar. Geol. 385, 41-

93855.

939 Castelle, B., Dodet, G., Masselink, G., Scott, T., 2017b. A new climate

940 index controlling winter wave activity along the Atlantic coast of

941 Europe: the West Europe Pressure Anomaly. Geophys. Res. Lett. 44.

942 Castelle, B., Dodet, G., Masselink, G., Scott, T., in prep. Increased

943 winter-mean wave height, variability and periodicity in the North-

944 east Atlantic over 1949-2017. Geophys. Res. Lett. 
945 Ciavola, P., Coco, G., 2017. Coastal Storms: Processes and Impacts.

946 Wiley, 1-22.

947 Choowong, M., Phantuwongraj, S., Charoentitirat, T.,

948 Chutakositkanon, V., Yumuang, S., Charusiri, P., 2009. Beach

949 recovery after 2004 Indian Ocean tsunami from Phang-nga,

950 Thailand. Geomorphology 104, 134-142.

951 Coco, G., Senechal, N., Rejas, A., Bryan, K.R., Capo, S., Parisot, J.P.,

952 Brown, J.A, MacMahan, J.H.M., 2014. Beach response to a sequence

953 of extreme storms. Geomorphology 204, 493-501.

954 Corbella, S., Stretch, D.D., 2012. Shoreline recovery from storms on

955 the east coast of Southern Africa. Nat. Hazards Earth Syst. Sci. 12,

$956 \quad 11-22$.

957 Davidson, M.A., Turner, I.L., 2009. A behavioral template beach

958 profile model for predicting seasonal to interannual shoreline

959 evolution. J. Geol. Res. 114, F01020.

960 Davidson, M.A., Lewis, R.P., Turner, I.L., 2010. Forecasting seasonal

961 to multi-year shoreline change. Coast. Eng. 57, 620-629.

962 Davidson, M.A., Splinter, K.D., Turner, I.L., 2013. A simple

963 equilibrium model for predicting shoreline change. Coast. Eng. 73,

964 191-202.

965 Davidson, M.A., Turner, I.A., Splinter, K.D., Harley, M.D., 2017.

966 Annual prediction of shoreline erosion and subsequent recovery.

967 Coast. Eng. 130, 14-25. 

volume in Delaware. Mar. Geol. 81 (1), 79-96.

971 Robinson, N., Andrews, M., Knight, J., 2016. Skilful predictions of the

972 winter North Atlantic Oscillation one year ahead. Nat. Geosci. 9,

$973809-814$.

974 Ge, Z., Dai, Z., Pang, W., Li, S., Wei, W., Mei, X., Huang, H., Gu, J.,

975 2017. LiDAR-based detection of the post-typhoon recovery of a

976 meso-macro-tidal beach in the Beibu Gulf, China. Mar. Geol. 391,

$977 \quad 127-143$.

978 Harley, M.D., Turner, I.L., Splinter, K.D., Phillips, M.S., Simmons, J.A., 979 2016. Beach response to Australian East Coast Lows: a comparison

980 between the 2007 and 2015 events, Narrabeen-Collaroy Beach. J.

981 Coast. Res. 75 (SI), 388-392.

982 Harley, M.D., Turner, I.L., Kinsela, M.A., Middleton, J.H., Mumford,

983 P.J., Splinter, K.D., Phillips, M.S., Simmons, J.A., Hanslow, D.J., Short,

984 A.D., 2017a. Extreme coastal erosion enhanced by anomalous

985 extratropical storm wave direction. Scientific Reports 7, 6033.

986 Harley, M.D., Turner, I.L., Middleton, J.H., Kinsela, M.A., Hanslow, D.,

987 Splinter, K.D., Mumford, P., 2017b. Observations of beach recovery

988 in SE Australia following the June 2016 east coast low. Coasts \&

989 Ports 2017 Conference - Cairns, Australia. 
990 Houser, C., Greenwood, B., 2005. Profile response of a lacustrine

991 multiple barred nearshore to a sequence of storm events.

992 Geomorphology 69, 118-137.

993 Houser, C., Wernette, P., Rentschlar, E., Jones, H., Hammond, B.,

994 Trimble, S., 2015. Post-storm beach and dune recovery: Implications

995 for barrier island resilience. Geomorphology 234, 54-63.

996 Hulme, M., 1997. The climate in the UK from November 1994 to

997 October 1995. Weather 52 (8), 242-257.

998 Komar, P.D., 1999. Beach processes and sedimentation. Prentice-

999 Hall, New Jersey, p. 544.

1000 Lozano, I., Devoy, R.J.N., May, W., Andersen, U., 2004. Storminess

1001 and vulnerability along the Atlantic coastlines of Europe: analysis of

1002 storm records and of a greenhouse gases induced climate scenario.

1003 Mar. Geol. 210, 205-225.

1004 Masselink, G., Scott, T., Davidson, M., Russell, P., Conley, D., 2015.

1005 The extreme 2013/2014 winter storms: hydrodynamic forcing and

1006 coastal response along the southwest coast of England. Earth Surf.

1007 Process. Landf. 41, 378-391.

1008 Masselink, G., Castelle, B., Scott, T., Dodet, G., Suanez, S., Jackson,

1009 D., Floc'h, F., 2016. Extreme wave activity during 2013/2014 winter

1010 and morphological impacts along the Atlantic coast of Europe,

1011 Geophys. Res. Lett. 43, 2135-2143. 
1014 McCallum, E., Grahame, N.S., 1993. The Braer storm - 10 January 1015 1993. Weather 48 (4), 103-107.

1016 McLean, R., Shen, J.S., 2006. From foreshore to foredune: foredune 1017 development over the last 30 years at Moruya Beach, New South 1018 Wales, Australia. J. Coast. Res. 22, 28-36.

1019 Miller, J.K., Dean, R.G., 2004. A simple new shoreline model. Coast. 1020 Eng. 51, 531-556.

1021 Morton, R.A., Paine, J.G., Gibeaut, J.C., 1994. Stages and Durations 1022 of post-Storm Beach Recovery, Southeastern Texas Coast, U.S.A. J. 1023 Coast. Res. 10 (4), 884-908.

1024 Phillips, M.S., Harley, M.D., Turner, I.L., Splinter, K.D., Cox, R.J., 2017. 1025 Shoreline recovery on wave-dominated sandy coastlines: the role of 1026 sandbar morphodynamics and nearshore wave parameters. Mar. 1027 Geol. 385, 146-159.

1028 Plant, N.G., Holman, R.A., Freilich, M.H., Birkemeier, W.A., 1999. A 1029 simple model for interannual sandbar behavior. J. Geoph. Res. 104 1030 (C7), 15,755-15,776.

1031 Poate, T., Masselink, Russell, P., Austin, M., 2014. Morphodynamic 1032 variability of high-energy macrotidal beaches, Cornwall, UK. Mar. 1033 Geol. 350, 97-111. 
Poate, T., Masselink, G., McCall, R., Russell, P., Davidson, M., 2015.

UK storms 2014: gravel beach response. Proceedings Coastal Sediments, ASCE, San Diego, USA.

Prodger, S., Russell, P., Davidson, M., Miles, J., Scott, T., 2016.

Understanding and predicting the temporal variability in sediment grain size characteristics on high energy beaches. Mar. Geol. 376, 109-117.

Pye, K., Blott, S.J., 2008. Decadal-scale variation in dune erosion and accretion rates: An investigation of the significance of changing storm tide frequency and magnitude on the Sefton coast, UK. Geomorphology 102, 652-666.

Pye, K., Blott, S.J., 2016. Assessment of beach and dune erosion and accretion using LiDAR: Impact of the stormy 2013-14 winter and longer term trends on the Sefton Coast, UK. Geomorphology 266, $146-167$

Roberts, T.M., Wang, P., Puleo, J.A., 2013. Storm-driven cyclic beach morphodynamics of a mixed sand and gravel beach along the MidAtlantic Coast, USA. Mar. Geol. 346, 403-421.

Robinet, A., Castelle, B., Idier, I., Le Cozannet, G., Deque, M., Charles, E., 2016. Statistical modelling of interannual shoreline change driven by North Atlantic climate variability spanning 20002014 in the Bay of Biscay. Geo. Mar. Lett. 36, 479-490. 
Ruggiero, P., Kaminsky, G.M., Gelfenbaum, G., Voigt, B., 2005.

Sallenger, A.H., 2000. Strom Impact Scale for Barrier Islands. J.

Coast. Res. 16 (3), 890-895.

1061

Saulter, A., 2017. North West European Shelf Production Centre NORTHWESTSHELF_ANALYSIS_FORECAST_WAV_004_012 Quality Information Document. Copernicus Marine Environment Monitoring service.

Senechal, N., Gouriou, T., Castelle, B., Parisot, J.-P., Capo, S., Bujan, S., Howa, H., 2009. Morphodynamic response of a meso- to macrotidal intermediate beach based on a long-term data set. Geomorphology 107, 263-274. on the seasonal shoreline dynamics of a meso- to macrotidal open sandy beach (Biscarrosse, France). Geomorphology 228, 448-461. in the UK. (Ph.D. thesis). University of Plymouth.

1075 characteristics and classification of beaches in England and Wales.

1076 Mar. Geol. 286, 1-20.

1077 Scott, T., Masselink, G., O’Hare, T., Saulter, A., Poate, T., Russell, P., 1078 Davidson, M., Conley, D., 2016. The extreme 2013/2014 winter 
storms: Beach recovery along the southwest coast of England. Mar.

1080 Geol. 382, 224-241.

1081

Short, A.D., Bracs, M.A., Turner, I.L., 2014. Beach oscillation and

1082 rotation: local and regional response at three beaches in southeast

1083 Australia. J. Coast. Res. 70 (SI), 712-717.

1084

Splinter, K.D., Strauss, D.R., Tomlinson, R.B., 2011. Assessment of

1085 post-storm recovery of beaches using video imaging techniques: a

1086 case study at Gold Coast, Australia. IEEE Trans. Geosci. Remote Sens. 49 (12), 4704-4716.

1088

Splinter, K.D., Turner, I.L., Davidson, M.A., 2013. How much data is

1089 enough? The importance of morphological sampling interval and

1090 duration for calibration of empirical shoreline models. Coast. Eng.

1091 $77,14-27$.

1092 Splinter, K.D., Turner, I.L., Davidson, M.A., Barnard, P., Castelle, B., 1093 Oltman-Shay, J., 2014. A generalized equilibrium model for 1094 predicting daily to interannual shoreline response. J. Geophys. Res. 1095 Earth Surf. 119, 1936-1958.

1096 Stive, M.J.F., Aarninkhof, S.G.J., Hamm, L., Hanson, H., Larson, 1097 M.,Wijnberg, K.M., Nicholls, R.J., Capobianco, M., 2002. Variability of 1098 shore and shoreline evolution. Coast. Eng. 47, 211-235.

1099 Stockdon, H.F., Holman, R.A., Howd, P.A., Sallenger, A.H., 2006.

1100 Empirical parameterization of setup, swash, and runup. Coast. Eng.

$110153,573-588$. 
Suanez, S., Cariolet, J.M., Cancouët, R., Ardhuin, F., Delacourt, C., 2012. Dune recovery after storm erosion on a high-energy beach: Vougot Beach, Brittany (France). Geomorphology 139-140, 16-33.

1105 Sutherland, J., Peet, A.H., Soulsby, R.L., 2004. Evaluating the

1106 performance of morphological models. Coast. Eng. 51, 917-939.

1107 Thom, B.H., Hall, W., 1991. Behaviour of beach profiles during

1108 accretion and erosion dominated period. Earth Surf. Process. Landf.

$110916,113-127$.

1110 Turner, I.L., Harley, M.D., Short, A.D., Simmons, J.A., Bracs, M.A.,

1111 Phillips, M.S., Splinter, K.D., 2016. A multi-decade dataset of

1112 monthly beach profile surveys and inshore wave forcing at

1113 Narrabeen, Australia. Scientific Data 3, 160024.

1114 Valiente, N.G., Masselink, G., Scott, T., Conley, D., McCarroll, R.J., in

1115 prep. Depth of closure: a multi-criteria approach for a macrotidal,

1116 embayed and exposed coast. J. Geophy. Res.

1117 Vousdoukas, M.I., Almeida, L.P.M., Ferreira, Ó., 2012. Beach erosion

1118 and recovery during consecutive storms at a steep-sloping, meso-

1119 tidal beach. Earth Surf. Process. Landf. 37 (6), 583-593.

1120 Wang, P., Kirby, J.H., Haber, J.D., Horwitz, M.H., Knorr, P.O., Krock,

1121 J.R., 2006. Morphological and sedimentological impacts of hurricane

1122 Ivan and immediate post-storm beach recovery along the

1123 Northwestern Florida barrier-island coasts. J. Coast. Res. 6, 1382-

11241402. 
1125 Wiggins, M., Scott, T., Masselink, G., Russell, P., in prep. Controls on

1126 full embayment sediment dynamics: a decade of multi-method

1127 surveys.

1128 Wright, L.D., Short, A.D., 1984. Morphodynamic variability of surf

1129 zones and beaches: a synthesis. Mar. Geol. 56, 93-118.

1130 Wright, L.D., Short, A.D., Green, M.O., 1985. Short-term changes in

1131 the morphodynamic states of beaches and surf zones; an empirical

1132 predictive model. Mar. Geol. 62, 339-364.

1133 Yu, F., Switzer, A.D., Lau, A.Y.A, Yeung, H.Y.E, Chik, S.W., Chiu, H.C.,

1134 Huang, Z., Pile, J., 2013. A comparison of the post-storm recovery of

1135 two sandy beaches on Hong Kong Island, southern China.

1136 Quaternary International 304, 163-175.

1137 Zhang, K., Douglas, B., Leatherman, S., 2002. Do Storms Cause Long-

1138 Term Beach Erosion along the U.S. East Barrier Coast? J. Geol. 110

1139 (4), 493-502.

1140 Figure and table captions

1141 Figure 1. Bathymetric map of southwest England with the location of

1142 the 10 study sites, Perranporth (PPT) wave buoy, Port Isaac (PI) tidal

1143 gauge, the 8-km WWIII modelled wave node and the depth contour

1144 representing the 30-m line (left panel). The bar graphs and wave roses

1145 represent, respectively, monthly-averaged wave conditions $\left(H_{s}\right.$ and $\left.T_{p}\right)$

1146 and winter/summer wave direction recorded by the Perranporth

1147 wave buoy from 2007 to 2017. 

geomorphological diversity of the 10 study sites (Widemouth \#1, Constantine \#2, Porthcothan \#3, Trenance \#4, Watergate \#5, Porth \#6, Fistral \#7, Porthtowan \#8, Gwithian \#9 and Sennen \#10 beaches). All pictures are oriented according to north-south axis and the beach profile surveyed by the Plymouth Coastal Observatory are located with dashed white lines.

Figure 3. RTK-GPS cross-shore profiles of Porthcothan \#3 (left panel) and Trenance \#4 (right panel) beaches, where vertical beach and dune areas are highlighted according to the different topographic and water levels ( $z_{\max }$ : fixed backshore topographic point; $z_{\min }$ : lowest topographic point; MHWS: mean high water spring; MSL: mean sea level; MLWS: mean low water spring).

Figure 4. Scatter plots of measured and modelled (a) significant wave height, $H_{s}$, and (b) peak wave period, $T_{p}$, from 2007 to 2017. Measured wave data were obtained from the Perranporth wave buoy (16 $\mathrm{m}$ deep) managed by the Channel Coastal Observatory, and 8-km WaveWatch III modelled wave data ( $50 \mathrm{~m}$ deep) were provided by the MetOffice.

Figure 5. Time series from 1980 to 2017 of: (a) 3-hourly modelled significant wave height $H_{s}$ (grey) and 8-weeks block-averaged wave significant wave height (black); (b) 3-hourly modelled peak wave period $T_{p}$ (grey) and 8-week averaged peak wave period (black) at modelled grid point; and (c) winter WEPA index (DJFM). The red dashed-square represent the 10-year study period for which beach 

provided in Tables 3 and 4.

1175 Figure 6. Scatter plots of the winter-mean (DJFM) modelled 1176 significant wave height, $H_{\text {s mean }}$, and the winter WEPA index (a) from 1177 the $1980 / 81$ to the $2016 / 17$ winter; and (b) from the $2007 / 08$ to the 1178 2016/17 winter.

1179 Figure 7. Time series of significant wave height $H_{s}(\mathrm{~m})$, water level (m 1180 above Ordnance Datum, OD) and storm threshold ( $H_{s} 1 \%$ exceedance $)$ 1181 during the winter of: (a) 2013/14; (b) 2015/16; and (c) 2016/2017. 1182 Storms that occurred during spring tides are highlighted by red dots.

1183 Figure 8. Three representative examples of RTK-GPS cross-shore 1184 profiles showing the 2011/12 winter (top panels), 2013/14 winter 1185 (middle panels) and the 2016 summer (bottom panels) beach 1186 responses at Constantine \#2, Trenance \#4 and Fistral \#7 beaches. 1187 Antecedent and subsequent profiles are, respectively, coloured in 1188 blue and red, while all other profiles from Autumn 2007 to Spring 11892017 are coloured in grey. Beach profiles are also presented on a 1190 variable vertical scale to give a better visualization of the 1191 morphological changes at beaches where dunes are not present.

1192 Figure 9. Time series from 2007 to 2017 of the longshore-averaged 1193 beach volume time-series $V\left(\mathrm{~m}^{3} \mathrm{~m}^{-1}\right)$ for the 10 study sites.

1194 Figure 10. Time series from 2007 to 2017 of: (a) the average of the 10 1195 beach volume time-series, $V_{\text {avg }}\left(\mathrm{m}^{3} \cdot \mathrm{m}^{-1}\right)$ in black bounded by its 1196 standard deviation in grey; (b) 3-hourly modelled significant wave 
height $H_{s}$ (grey) and 8-week block-averaged significant wave height

1198 (black); and (c) winter WEPA index. Surveys in spring (end of winter)

1199 each year are indicated with black dots to highlight seasonal

1200 variations in the beach volume time-series.

1201 Figure 11. Time series of 6-monthly average of longshore averaged

1202 beach volumes changes $d V_{\text {mean }}\left(\mathrm{m}^{3} \mathrm{~m}^{-1}\right)$ and 6-monthly average

1203 significant wave height $H_{s}$ mean during winter (upper panel) and

1204 summer (lower panel) months, from 2007 to 2017. The error bars

1205 represent the standard deviation in volume change. Watergate \#5

1206 and Gwithian \#9 were not incorporated because they were only

1207 yearly surveyed.

1208 Figure 12. Scatter plots of the 10 beaches average standard deviation

1209 of 6-monthly volume changes, $d V_{\text {std }}$, and the corresponding 6-

1210 monthly significant wave height mean values, $H_{\text {s mean }}$, over (a) winter

1211 months, and (b) summer months from 2007 to 2017.

1212 Figure 13. Longshore-averaged dunes and intertidal beach volume

1213 time series $\left(V_{\text {dunes, }}, V_{\text {beach }}\right)$ from 2007 to 2017 at Widemouth \#1,

1214 Constantine \#2, Porthcothan \#3, Gwithian \#9 and Sennen \#10

1215 beaches (left panel). The vertical scale between each tick mark

1216 represents a $100 \mathrm{~m}^{-3} \mathrm{~m}^{-1}$ volume change. Pre-storm (Autumn 2013),

1217 post-storm (Spring 2013) and last (Spring 2017) RTK-GPS cross-shore

1218 profiles showing dune erosion and recovery at three representative

1219 beaches: Constantine \#2, Porthcothan \#3, and Sennen \#10 (right

1220 panel). Autumn 2013, Spring 2014 and Spring 2017 profiles are

1221 respectively coloured in blue, red and black and the beach profiles 

interest (dunes).

1224 Figure 14. Scatter plot of 6-monthly beach volumes changes, $d V$, with

1225 (a) the corresponding 6-monthly significant wave height mean values

$1226 H_{s \text { mean }}$ and (b) the 6-monthly cumulative storm duration, at the 10

1227 study sites represented by different colours (same code of colours

1228 relative to Fig. 9). Interpreted threshold of $H_{s \text { mean }}$ is indicated by the

1229 grey band. For every beach, each 6-monthly volume change $d V$ value

1230 is attributed to a 6-monthly wave height mean $H_{s}$ or storm duration

1231 value, a same value of wave height/storm duration can therefore correspond to several summer or winter periods. Watergate \#5 and Gwithian \#9 were not incorporated because they were only yearly

1234 surveyed.

Figure 15. Time series from 2007 to 2017 of: (a) 3-hourly modelled model results represented by the thick black line.

Figure 16. Scatter plots of the winter WEPA index with (a) the average of the 10 beach observed winter volumes changes, and (b) the average of the 10 beach modelled winter volumes changes from the $2007 / 08$ to the $2016 / 17$ winter. 
Table 1. Key beach characteristics and RTK-GPS profile surveyed at the 10 study sites. $L$ : longshore beach length in $\mathrm{m}$; $d 50$ : beach grain

1247 size in mm along the upper/lower part of the beach (Scott et al., 2008); $\alpha$ : clockwise beach angle orientation compare to the north-south axis; number of beach RTK-GPS profiles surveyed; percentage of beach profiles surveyed going through dune system; MSR: mean spring tidal range (in $\mathrm{m}$ ).

Table 2. Survey dates of the RTK-GPS beach profiles from 2007 to 2017 at the 10 study sites. Surveys were carried out by the Plymouth Coastal Observatory.

Table 3. Winter-mean values (from October to March) of significant wave height $H_{s}(\mathrm{~m})$, wave peak period $T_{p}(\mathrm{~s})$, number of storms, mean duration of storms (h), cumulative storm duration (h) and energetic rank based on wave energy level, from the $2006 / 07$ to the $2016 / 17$ winter.

1260 Table 4. Summer-mean (from April to September) values of 1261 significant wave height $H_{s}(\mathrm{~m})$, wave peak period $T_{p}(\mathrm{~s})$, number of 1262 storms, mean duration of storms (h), cumulative storm duration (h) 1263 and energetic rank based on wave energy level, during summer months from 2007 to 2016. 